\title{
Cost-effectiveness of Increasing Access to Contraception during the Zika Virus Outbreak, Puerto Rico, 2016
}

\author{
Rui Li, Katharine B. Simmons, Jeanne Bertolli, Brenda Rivera-Garcia, Shanna Cox, \\ Lisa Romero, Lisa M. Koonin, Miguel Valencia-Prado, Nabal Bracero, Denise J. Jamieson, \\ Wanda Barfield, Cynthia A. Moore, Cara T. Mai, Lauren C. Korhonen, Meghan T. Frey, \\ Janice Perez-Padilla, Ricardo Torres-Muñoz, Scott D. Grosse
}

We modeled the potential cost-effectiveness of increasing access to contraception in Puerto Rico during a Zika virus outbreak. The intervention is projected to cost an additional $\$ 33.5$ million in family planning services and is likely to be cost-saving for the healthcare system overall. It could reduce Zika virus-related costs by $\$ 65.2$ million (\$2.8 million from less Zika virus testing and monitoring and $\$ 62.3$ million from avoided costs of Zika virus-associated microcephaly [ZAM]). The estimates are influenced by the contraception methods used, the frequency of ZAM, and the lifetime incremental cost of ZAM. Accounting for unwanted pregnancies that are prevented, irrespective of Zika virus infection, an additional $\$ 40.4$ million in medical costs would be avoided through the intervention. Increasing contraceptive access for women who want to delay or avoid pregnancy in Puerto Rico during a Zika virus outbreak can substantially reduce the number of cases of ZAM and healthcare costs.

$\mathrm{Z}$ ika virus infection during pregnancy can cause microcephaly with severe brain damage in the fetus (referred to here as Zika virus-associated microcephaly [ZAM] ) and is linked to pregnancy loss and to problems in infants, including eye defects, hearing loss, and impaired growth (1). Zika virus is a flavivirus transmitted primarily by infected Aedes species mosquitos (2). Zika virus can also be sexually transmitted (3). Puerto Rico

Author affiliations: Centers for Disease Control and Prevention, Atlanta, Georgia, USA (R. Li, K.B. Simmons, J. Bertolli,

S. Cox, L. Romero, L.M. Koonin, D.J. Jamieson, W. Barfield, C.A. Moore, C.T. Mai, L.C. Korhonen, M.T. Frey, J. Perez-Padilla,

S.D. Grosse); Puerto Rico Department of Health, San Juan,

Puerto Rico (B. Rivera-Garcia, M. Valenica-Prado,

R. Torres-Muñoz); University of Puerto Rico and Puerto Rico

Section of the American College of Obstetricians and

Gynecologists, San Juan (N. Bracero)

DOI: http://dx.doi.org/10.3201/eid2301.161322 has the largest number of Zika virus disease cases in the United States and its territories (4) and, based on extrapolations from the experiences of other countries with Zika virus outbreaks, will probably experience large numbers of Zika virus-exposed pregnancies (5).

A primary strategy to reduce Zika virus-associated adverse pregnancy outcomes is to assist women who want to delay or avoid pregnancy. An estimated $65 \%$ of pregnancies in Puerto Rico are unintended (unwanted or mistimed), compared with $45 \%$ in the continental United States $(2,0)$. Women in Puerto Rico face multiple barriers to contraceptive use, including high out-of-pocket costs, a shortage of contraceptive supplies, lack of education about options, and a limited number of family planning delivery sites (2).

In response to the Zika virus outbreak, the Centers for Disease Control and Prevention and other federal and local partners are seeking to improve access to contraception for women in Puerto Rico who desire it but encounter barriers to accessing the full range of contraception methods, including long-acting reversible contraceptives (LARCs). The objective of this analysis was to estimate the potential cost-effectiveness of increasing access to contraception in Puerto Rico during the 2016 Zika virus outbreak.

\section{Methods}

We constructed a decision tree cost-effectiveness model for a target population of 163,000 women who at the time of the intervention are sexually active with a male partner, fertile, not desiring pregnancy within the next 12 months, and not using permanent contraception methods (e.g., tubal ligation and vasectomy) (online Technical Appendix Table and Figure 1, http://wwwnc.cdc.gov/EID/ article/23/1/16-1322-Techapp1.pdf). In the no intervention scenario, no changes in contraceptive use distributions from the status quo are expected to occur. In the intervention scenario, women in Puerto Rico are assumed to 
have same-day access to contraception methods, including LARC, with no out-of-pocket costs. In addition, healthcare providers would be trained to provide client-centered contraceptive counseling and outreach so that women have the information they need to make an informed choice on the contraception method that is best for them. The model specifies contraceptive method use distribution, unintended pregnancy events, and the frequency of ZAM (online Technical Appendix Figure 1).

We assumed an intervention in place throughout a year-long Zika virus outbreak in Puerto Rico. We evaluated the costs and outcomes of increased access to contraception compared with no intervention (i.e., status quo). Output measures included numbers of ZAM cases prevented, including stillbirths, elective terminations, and live-born infants, and healthy life years (HLY) gained. Economic benefits of the intervention included avoided costs from ZAM cases prevented and costs avoided for monitoring for Zika virus-exposed pregnancies and infants born from Zika virus-infected mothers. In addition, the avoided cost of prenatal, delivery, postpartum, and neonatal care associated with avoided unwanted pregnancies was considered an economic benefit. In cost-effectiveness analyses, if total avoided cost exceeds the cost of an intervention that improves health, the intervention is considered cost-saving. For scenarios with positive net costs, we reported the incremental cost-effectiveness ratio (ICER), which is the net cost per HLY gained in comparison to the status quo.

Independent of Zika virus-exposed pregnancies and ZAM, unintended pregnancy is associated with adverse maternal and child health outcomes. Because roughly $60 \%$ of unintended pregnancies are classified as mistimed, which might result in a delayed rather than avoided pregnancy, with the same costs occurring later (7), we only estimated avoided medical costs from prevention of the $40 \%$ of unintended pregnancies presumed to be not desired at a later time irrespective of Zika virus infection. However, we included all ZAM cases prevented during the intervention period.

\section{Contraception Use with and without the Intervention}

We estimated the inputs for the decision-tree model and their sources (Table 1, http://wwwnc.cdc.gov/EID/ article/23/1/16-1322-T1.htm). In the no intervention scenario, we took the distribution of women in the target population by use of different types of reversible contraceptives (or no use) from a 2002 survey administered in Puerto Rico and adjusted it to reflect the $36 \%$ decrease in fertility rates in Puerto Rico during 2002-2015 (8,23,24).

For the main intervention scenario, we assumed that $50 \%$ of no contraception users, $60 \%$ of less-effective contraceptive method users, and $100 \%$ of moderately effective contraceptive method users would visit a healthcare provider during the intervention period and be counseled about contraception use (Table 1). The first 2 percentages are roughly twice the percentages of women reported in the 2011-2013 US National Survey on Family Growth to have received contraceptive services (contraception or counseling) within the past year because we assumed that, during the Zika virus outbreak, more women and providers would discuss contraception; virtually all moderately effective method users were assumed to see providers to obtain contraceptive prescriptions.

For the main scenario, we also assumed, optimistically, that $50 \%$ of women in the target population who receive contraceptive services during the Zika virus outbreak would be willing to change to a more effective contraceptive method, evenly divided between moderately effective and highly effective methods. We applied data from the Contraceptive CHOICE Project (67\% of participants used LARC and 33\% used moderately effective methods) (9) to the $40 \%$ of women assumed to not want to be pregnant; we assumed $20 \%$ of other women not intending pregnancy would use LARC. We further assumed that $30 \%$ of moderately effective contraception users would also choose to use condoms (dual-method use) under the intervention, based on a study reporting dual-method use among persons at risk for HIV (25).

\section{Epidemiologic Model Input Parameters}

We calculated method-specific annual pregnancy rates by applying failure rates of contraception methods under typical use (10), in combination with information on estimated numbers of unintended pregnancies, to adjust for other factors influencing pregnancy risk (19). We estimated the proportion of fetal losses among unintended pregnancies from data for the Caribbean region, including Puerto Rico (12), and calculated the proportion of induced abortion among unintended pregnancies from a survey conducted in Puerto Rico in 2001 (the latest year for which data were available) (11). We assumed that the distribution of fetal loss and induced abortions in unintended pregnancies unaffected by ZAM would not be altered by the Zika virus outbreak or the intervention.

For adverse pregnancy and birth outcomes associated with Zika virus, we only considered ZAM and associated brain anomalies, including live births, stillbirths, and terminations attributable to prenatal diagnosis. Although Zika virus can cause brain lesions and dysfunction in fetuses and newborns who do not have microcephaly (26), we lacked the data to model their prevalence and cost. In the main analysis, we assumed 58 cases of ZAM per 10,000 live births (range 32-86/10,000) based on a modeling study that considered data from other mosquitoborne illnesses in Puerto Rico and Zika virus outbreaks in other locations (5). We assumed a pregnancy loss rate of $35 \%$ among Zika 
virus-exposed fetuses with diagnosed birth defects based on cases in the US Zika Pregnancy Registry as of July 21, 2016 (14).

A summary measure of population health impact is healthy life expectancy at birth. We projected gains in HLY by multiplying total cases of ZAM prevented by 30.0 , which is the average number of quality-adjusted life-years at birth in the United States for an infant without severe microcephaly (15) and the estimated loss in disability-adjusted life years from microcephaly (27). We multiplied 30.0 by the sum of live births and fetal losses associated with ZAM to calculate gains in HLY. We included fetal losses in the HLY calculations because in the absence of ZAM those pregnancies would have resulted in live births, with the same healthy life expectancy as other children (15).

\section{Cost Parameters}

We conducted the analysis from a healthcare system perspective that includes direct medically related costs regardless of payer. We used payments from private insurance because payments from Medicaid might underestimate the cost of healthcare (28). Intervention costs included program costs of training providers, patient educational materials, outreach/media campaigns on the availability of contraceptives services, and program coordination and the incremental costs of family planning services. The latter comprised the costs of contraception methods and related office visits and services (e.g., insertion and removal of LARC for new method users resulting from the intervention and the cost of more intensive counseling for all women receiving contraceptive services during the intervention). We took the 1 -year costs for contraception methods from the literature $(16,29)$ and based the other program costs on the estimated costs for a pilot program planned to increase access to contraception in Puerto Rico as part of the current Zika virus outbreak response (30). We did not apply a discount rate to intervention costs because of the time horizon of 12 months.

Zika virus-related costs prevented by this intervention were in 2 parts: 1) costs for Zika virus testing and monitoring for Zika virus-exposed pregnancies and infants, and 2) costs of ZAM cases (Table 1). The cost estimates for testing and monitoring presumed $100 \%$ adherence by clinicians and patients to recommendations (20-22).

The lifetime cost per live-born infant with ZAM includes direct medical and nonmedical costs. ZAM is among the most severe types of microcephaly and is associated with loss of brain tissue volume, increased fluid spaces, and intracranial calcifications. All 3 cases of live-born infants with ZAM in French Polynesia demonstrated severe neurologic outcomes with delayed cognitive development (26). On the basis of expert opinion, infants with ZAM who survive the neonatal period would be expected to have neurologic dysfunction consistent with severe cerebral palsy within 1-2 years of birth.

As a proxy for the medical cost of ZAM, we used the estimated cost of treating infants with microcephaly associated with a diagnosis of symptomatic congenital cytomegalovirus (CMV). We used the MarketScan Commercial Database (Truven Health Analytics) with a sample of $\approx 100$ million US residents covered by employer-sponsored insurance at any time during 2009-2014. We used average costs for 4 newborn infants with diagnoses of microcephaly and CMV who survived and were enrolled in a health plan for $\geq 3$ years. For the direct nonmedical cost of ZAM, we used the estimated cost for supportive care for children with severe congenital brain injury, both paid care and unpaid care. The total lifetime cost for surviving infants with ZAM was estimated at $\$ 3.8$ million per infant, taking into account infant and child mortality and discounting of costs in future years at a $3 \%$ rate per year; the sum of undiscounted costs for children who survive to adulthood might reach $\$ 10$ million.

We determined the estimated non-Zika virus-related medical costs associated with women's prenatal care, labor and delivery, and postpartum care for pregnancies ending in live birth and neonatal care from a study of US commercial health plan expenditures (17). Estimates for costs associated with pregnancies ending in induced abortion were based on our analyses of commercial claims data (Table 1).

\section{Sensitivity Analyses}

Because many parameters used in the model are uncertain, we conducted sensitivity analyses on selected parameters, including different scenarios for the baseline and postintervention contraception use distributions in Puerto Rico. We tested alternate baseline contraception use distributions in Puerto Rico for women at risk for unintended pregnancy by using the actual distribution of method use reported in 2002 (8) and among women attending Title X clinics in Puerto Rico in 2014 (31). For the postintervention contraception use distribution, we tested scenarios assuming different proportions of women receiving contraceptive services from a healthcare provider, different levels of willingness to switch to a more effective method, and different shares of moderately effective and highly effective methods among switchers. Other parameters evaluated during sensitivity analysis included the incidence of ZAM during the Zika virus outbreak in Puerto Rico, percentage of pregnancies with ZAM terminated, the cost of caring for a live-born infant with microcephaly, and the cost of the intervention.

We conducted sensitivity analyses in which we altered selected assumptions. In one, we annualized the cost of LARC devices considering the expected duration of method use. In another, we adjusted observed data on US healthcare and supportive care costs to the generally lower levels 


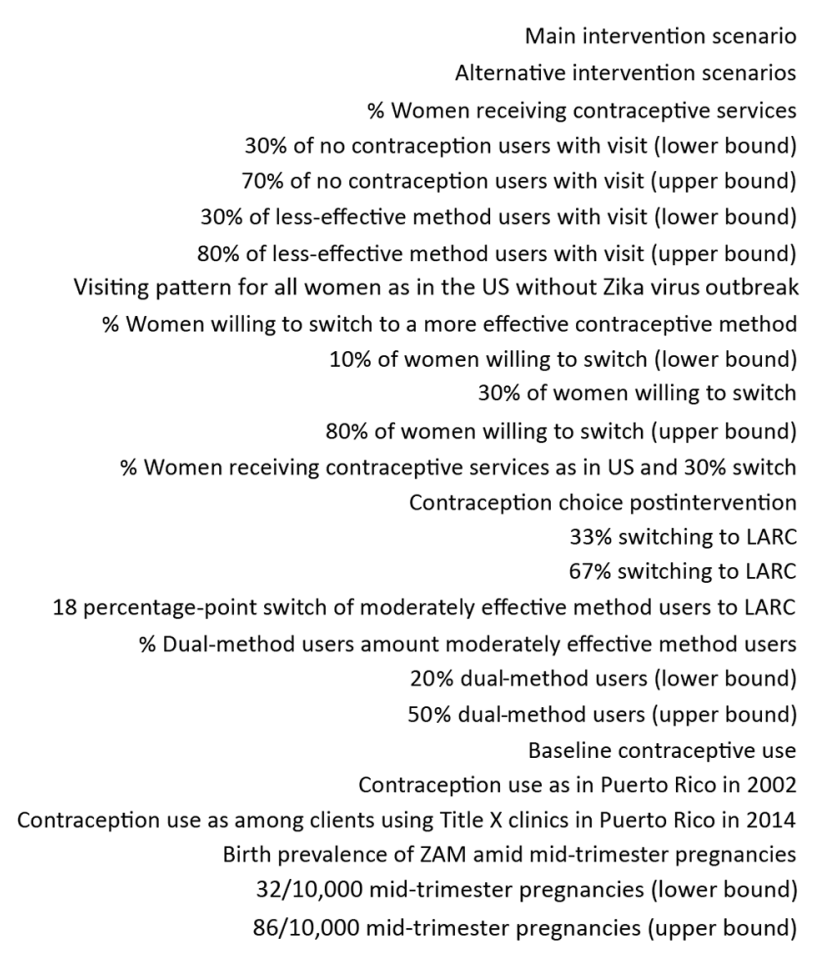

with an ICER of $\$ 24,608 / \mathrm{HLY}$ gained. Increasing the proportion of dual-method users increases the number of cases of ZAM prevented and net savings attributable to higher contraception effectiveness. The results are also sensitive to the prevalence of ZAM among mid-trimester pregnancies, the percentage of ZAM cases resulting in live-born infants, lifetime cost per live-born infant with ZAM, and the intervention cost. If we adjust US cost estimates for lower prices in Puerto Rico while keeping intervention costs at US prices, net savings are $\$ 1.7$ million. In all but 1 of the scenarios tested, the intervention is cost-saving.

A probabilistic sensitivity analysis scatter graph shows that most of the model simulations result in ICERs in the lower right quadrant with lower costs and better health outcomes (online Technical Appendix Figure 2). Specifically, the intervention is cost-saving in $92.11 \%$ of the 10,000 iterations, and in $98.10 \%$ of the iterations, the intervention has an ICER of $<\$ 20,000 /$ HLY gained.

The intervention is also predicted to prevent $\$ 40.4$ million in medical costs from unwanted pregnancies avoided in the main scenario (Table 2). In many sensitivity analyses, the cost avoided from these unwanted pregnancies prevented alone is greater than the intervention cost. The larger the numbers of no contraception users and less-effective method users receiving contraceptive services and willing to switch to more effective methods, the greater the magnitude of cost savings from unwanted pregnancies avoided (Table 3).
Figure. Sensitivity analysis indicating the effect of changes of assumptions on the number of ZAM cases prevented in a proposed intervention to increase access to contraception to women during the Zika virus outbreak, Puerto Rico, 2016. LARC, long-acting reversible contraceptive; ZAM, Zika virus-associated microcephaly.

\section{Discussion}

The results of our modeling analysis suggest that increasing access to effective contraception in the context of the 2016 Zika virus outbreak for women in Puerto Rico who do not intend to become pregnant could proportionally reduce the number of unintended pregnancies and cases of ZAM by $25 \%$. The intervention is cost-saving (negative net cost) when considering the benefits from preventing ZAM and avoiding Zika virus-exposed pregnancy costs in the main scenarios and in most of the scenarios we tested. In scenarios in which the intervention is not cost-saving, it is still cost-effective relative to accepted cost-effectiveness thresholds (35). The World Health Organization suggests that interventions that cost $<3$ times the gross domestic product per capita per HLY (equivalent to $\$ 150,000$ in the United States and $\$ 60,000$ in Puerto Rico) are cost-effective and those costing less than gross domestic product per capita are highly cost-effective (36). When considering additional benefits from preventing unintended pregnancies not desired at a later time, the intervention is cost-saving in all scenarios. Previous studies have shown that expanding access to contraception, especially LARC, is cost-saving $(16,37,38)$. Likewise, our findings suggest that this intervention could be cost-saving or cost-effective within the context of a public health emergency response.

Our study has several limitations. First, we project the effects of a hypothetical intervention in place in 
Puerto Rico during the 2016 Zika virus outbreak. However, the qualitative results would apply in future outbreaks. Second, the baseline contraception use distribution is based on a 2002 survey; the current distribution in Puerto Rico might be different. Third, uncertainty exists about the effect of the proposed intervention on postintervention contraceptive use distribution; however, the sensitivity analyses indicate that different distributions of LARC types among switchers does not have a substantial influence on the results. Fourth, our study assumes that women have full access to healthcare providers. In areas with limited access to providers, the effectiveness of the intervention might be lower, although Puerto Rico has a similar ratio of physicians to population as the United States as a whole (39), and despite a loss of physicians in recent years, Puerto Rico has a network of providers, federally qualified health clinics, and Title X providers in rural and urban areas. Fifth, the distribution of outcomes of unintended pregnancies in Puerto Rico is uncertain. We lack data on miscarriage and induced abortion rates in Puerto Rico and so did not have sufficient data to model uncertainty in these parameters. The rates of stillbirth and pregnancy termination among pregnancies with ZAM in Puerto Rico are also unknown. Our assumed percentage of live births among pregnancies with recognized ZAM (65\%) compares with a $38 \%$ rate reported in French Polynesia during the 2013 Zika virus outbreak (11). Sixth, pregnancy intentions and use of contraception among women in Puerto Rico might differ during the Zika virus outbreak compared to preoutbreak periods. Seventh, our analysis does not consider possibly higher rates of fetal loss and induced abortion among women infected by Zika virus during early pregnancy or brain abnormalities or conditions related to Zika virus not involving microcephaly. Eighth, the assumed Zika virus testing costs assume $100 \%$ adherence to recommended testing practices; the actual cost savings taking nonadherence into account would be lower. Ninth, the cost estimates of ZAM cases in live-born infants do not include costs of managing mental health conditions among parents of affected infants. Tenth, using private insurance payments might overstate the healthcare cost of treating ZAM. However, if the cost of ZAM exceeds $\$ 1.9$ million, the intervention is still cost-saving. Finally, if efforts to prevent transmission of Zika virus in Puerto Rico are effective, the rate of infection in pregnancy and the incidence of ZAM relative to that projected could be reduced.

Despite its limitations, our study has several strengths. First, the study is based on the most current available information. Second, the contraception scenarios are based on real-world programs and have resulted from consultation with subject matter experts. Third, expenditure data from a large sample of US residents with commercial health insurance were used to calculate the potential medical cost of ZAM on the basis of combinations of diagnostic codes for virus-associated microcephaly, although costs might be lower for similar children with public insurance. Finally, sensitivity analyses give consistent results indicating expected net cost savings associated with an intervention that would increase access to contraception in response to the Zika virus outbreak in Puerto Rico.

Zika virus can cause devastating birth defects, and infants born with ZAM and their families will require lifelong support. Avoiding unintended pregnancies is a critical intervention to mitigate the effects of ZAM. Efforts to prevent adverse Zika virus-related pregnancy outcomes in Puerto Rico are especially important because of limited resources (40). Our analyses suggest that increasing access to a full range of contraception among women in Puerto Rico who want to delay or avoid becoming pregnant during a Zika virus outbreak would be a cost-saving strategy to reduce the effects of ZAM. The magnitude of cost savings is even greater when considering the avoided cost of unwanted pregnancies prevented.

\section{Acknowledgments}

We thank Karen Pazol for providing data for input parameters on contraception failure rate for dual users and contraception service use, Martin Meltzer for providing invaluable comments on revising the manuscript, Hilary Whitham for providing consultation on TreeAge software and the decision tree structure, Loretta Gavin for providing data on contraception use in Title X clinics in Puerto Rico, Margaret (Peggy) Honein for leadership support, Annelise Arth for consulting on the cost of microcephaly, Matthew Biggerstaff for reviewing the decision tree, Alys Adamski for providing the most up-to-date $\mathrm{p}$ ublications related to Zika infection, Christine Olson and Romeo Galang for providing clinical information on Zika infection among pregnant women, Carrie Shapiro-Mendoza for reviewing the first round of analyses and providing feedback, and Howard Goldberg for consultation on the Puerto Rico contraceptive use distributions.

Dr. Li is the lead economist in the Division of Reproductive Health, National Center for Chronic Disease Prevention and Health Promotion, Centers for Disease Control and Prevention. Her expertise is health economics and economic evaluation.

\section{References}

1. Rasmussen SA, Jamieson DJ, Honein MA, Petersen LR. Zika virus and birth defects - reviewing the evidence for causality. N Engl J Med. 2016;374:1981-7. http://dx.doi.org/10.1056/ NEJMsr1604338

2. Tepper NK, Goldberg HI, Bernal MI, Rivera B, Frey MT, Malave C, et al. Estimating contraceptive needs and increasing access to contraception in response to the Zika virus disease outbreak-Puerto Rico, 2016. MMWR Morb Mortal Wkly Rep. 2016;65:311-4. http://dx.doi.org/10.15585/mmwr.mm6512e1 
3. Oster AM, Russell K, Stryker JE, Friedman A, Kachur RE, Petersen EE, et al. Update: interim guidance for prevention of sexual transmission of Zika virus-United States, 2016. MMWR Morb Mortal Wkly Rep. 2016;65:323-5. http://dx.doi.org/10.15585/mmwr.mm6512e3

4. Centers for Disease Control and Prevention. Zika virus disease in the United States, 2015-2016 [cited 2016 May 3]. http://www.cdc.gov/zika/geo/united-states.html

5. Ellington SR, Devine O, Bertolli J, Martinez Quiñones A, Shapiro-Mendoza CK, Perez-Padilla J, et al. Estimating the number of pregnant women infected with Zika virus and expected infants with microcephaly following the Zika outbreak in Puerto Rico, 2016. JAMA Pediatr. 2016 Aug 19 [Epub ahead of print].

6. Finer LB, Zolna MR. Declines in unintended pregnancy in the United States, 2008-2011. N Engl J Med. 2016;374:843-52. http://dx.doi.org/10.1056/NEJMsa1506575

7. Trussell J. Overstating the cost savings from contraceptive use. Eur J Contracept Reprod Health Care. 2008;13:219-21. http://dx.doi.org/10.1080/13625180802359263

8. Bensyl DM, Iuliano DA, Carter M, Santelli J, Gilbert BC. Contraceptive use: United States and territories, Behavioral Risk Factor Surveillance System, 2002. MMWR Surveill Summ. 2005;54:1-72.

9. Secura GM, Allsworth JE, Madden T, Mullersman JL, Peipert JF. The Contraceptive CHOICE Project: reducing barriers to longacting reversible contraception. Am J Obstet Gynecol. 2010;203:115.e1-7. http://dx.doi.org/10.1016/j.ajog.2010.04.017

10. Trussell J. Contraceptive failure in the United States. Contraception. 2011;83:397-404. http://dx.doi.org/10.1016/j. contraception.2011.01.021

11. Sedgh G, Singh S, Henshaw SK, Bankole A. Legal abortion worldwide in 2008: levels and recent trends. Int Perspect Sex Reprod Health. 2011;37:84-94. http://dx.doi.org/10.1363/3708411

12. Singh S, Sedgh G, Hussain R. Unintended pregnancy: worldwide levels, trends, and outcomes. Stud Fam Plann. 2010;41:241-50. http://dx.doi.org/10.1111/j.1728-4465.2010.00250.x

13. Cragan JD, Gilboa SM. Including prenatal diagnoses in birth defects monitoring: Experience of the Metropolitan Atlanta Congenital Defects Program. Birth Defects Res A Clin Mol Teratol. 2009;85:20-9. http://dx.doi.org/10.1002/bdra.20508

14. Centers for Disease Control and Prevention. Outcomes of pregnancies with laboratory evidence of possible Zika virus infection in the United States, 2016 [cited 2016 Jul 26]. https://www.cdc.gov/zika/geo/pregnancy-outcomes.html

15. Grosse SD, Ouyang L, Collins JS, Green D, Dean JH, Stevenson RE. Economic evaluation of a neural tube defect recurrence-prevention program. Am J Prev Med. 2008;35:572-7. http://dx.doi.org/10.1016/j.amepre.2008.07.008

16. Trussell J, Hassan F, Lowin J, Law A, Filonenko A. Achieving cost-neutrality with long-acting reversible contraceptive methods. Contraception. 2015;91:49-56. http://dx.doi.org/10.1016/ j.contraception.2014.08.011

17. Truven Health Analytics. The cost of having a baby in the United States [cited 2016 May 16]. http://transform.childbirthconnection. org/wp-content/uploads/2013/01/Cost-of-Having-a-Baby1.pdf

18. Biggio JR Jr, Morris TC, Owen J, Stringer JS. An outcomes analysis of five prenatal screening strategies for trisomy 21 in women younger than 35 years. Am J Obstet Gynecol. 2004;190:721-9. http://dx.doi.org/10.1016/j.ajog.2003.09.028

19. Santelli JS, Lindberg LD, Finer LB, Singh S. Explaining recent declines in adolescent pregnancy in the United States: the contribution of abstinence and improved contraceptive use. Am J Public Health. 2007;97:150-6. http://dx.doi.org/10.2105/ AJPH.2006.089169

20. Oduyebo T, Petersen EE, Rasmussen SA, Mead PS, Meaney-Delman D, Renquist CM, et al. Update: interim guidelines for health care providers caring for pregnant women and women of reproductive age with possible Zika virus exposure- - United States, 2016. MMWR Morb Mortal Wkly Rep. 2016;65:122-7. http://dx.doi.org/10.15585/mmwr.mm6505e2

21. Fleming-Dutra KE, Nelson JM, Fischer M, Staples JE, Karwowski MP, Mead P, et al. Update: interim guidelines for health care providers caring for infants and children with possible Zika virus infection - United States, February 2016. MMWR Morb Mortal Wkly Rep. 2016;65:182-7. http://dx.doi.org/10.15585/ mmwr.mm6507e1

22. Martines RB, Bhatnagar J, Keating MK, Silva-Flannery L, Muehlenbachs A, Gary J, et al. Notes from the field: evidence of Zika virus infection in brain and placental tissues from two congenitally infected newborns and two fetal losses-Brazil, 2015. MMWR Morb Mortal Wkly Rep. 2016;65:159-60. http://dx.doi.org/10.15585/mmwr.mm6506e1

23. Hamilton BE, Martin JA, Osterman MJ, Curtin SC, Matthews TJ. Births: Final Data for 2014. Natl Vital Stat Rep. 2015;64:1-64.

24. Martin JA, Hamilton BE, Sutton PD, Ventura SJ, Menacker F, Munson ML. Births: final data for 2002. Natl Vital Stat Rep. 2003;52:1-113.

25. Riehman KS, Sly DF, Soler H, Eberstein IW, Quadagno D, Harrison DF. Dual-method use among an ethnically diverse group of women at risk of HIV infection. Fam Plann Perspect. 1998;30:212-7. http://dx.doi.org/10.2307/2991606

26. Besnard M, Eyrolle-Guignot D, Guillemette-Artur P, Lastère $\mathrm{S}$, Bost-Bezeaud F, Marcelis L, et al. Congenital cerebral malformations and dysfunction in fetuses and newborns following the 2013 to 2014 Zika virus epidemic in French Polynesia. Euro Surveill. 2016;21:30181. http://dx.doi.org/10.2807/1560-7917. ES.2016.21.13.30181

27. Alfaro-Murillo JA, Parpia AS, Fitzpatrick MC, Tamagnan JA, Medlock J, Ndeffo-Mbah ML, et al. A cost-effectiveness tool for informing policies on Zika virus control. PLoS Negl Trop Dis. 2016;10:e0004743. http://dx.doi.org/10.1371/journal. pntd. 0004743

28. Broyles RS, Tyson JE, Swint JM. Have Medicaid reimbursements been a credible measure of the cost of pediatric care? Pediatrics. 1997;99:e8. http://dx.doi.org/10.1542/peds.99.3.e8

29. Trussell J, Lalla AM, Doan QV, Reyes E, Pinto L, Gricar J. Cost effectiveness of contraceptives in the United States. Contraception. 2009;79:5-14. http://dx.doi.org/10.1016/ j.contraception.2008.08.003

30. Arroyo MP. Contraceptive access due to Zika threat. Elnuevodia [cited 2016 Aug 4]. http://www.elnuevodia.com/english/english/ nota/contraceptiveaccessduetozikathreat-2227239

31. Fowler C, Gable J, Wang J, Lasater B. Title X family planning annual report: 2014 national summary. Research Triangle Park (NC): RTI International; 2015.

32. Portela M, Sommers BD. On the Outskirts of national health reform: a comparative assessment of health insurance and access to care in Puerto Rico and the United States. Milbank Q. 2015;93:584-608. http://dx.doi.org/10.1111/1468-0009.12138

33. Bureau of Labor Statistics. May 2015 state occupational employment and wage estimates: Puerto Rico [cited 2016 Jul 20]. http://www.bls.gov/oes/current/oes_pr.htm

34. Bureau of Economic Analysis. Table 2.5.4. Price indexes for personal consumption expenditures by function [cited 2016 Aug 5]. http://www.bea.gov/iTable/iTable.cfm?reqid=9\&step=3\&isuri=1\&9 $03=69$ \#reqid $=9 \&$ step $=3 \&$ isuri $=1 \& 903=73$

35. Grosse SD. Assessing cost-effectiveness in healthcare: history of the $\$ 50,000$ per QALY threshold. Expert Rev Pharmacoecon Outcomes Res. 2008;8:165-78. http://dx.doi.org/10.1586/14737167.8.2.165

36. McGann PT, Grosse SD, Santos B, de Oliveira V, Bernardino L, Kassebaum NJ, et al. A cost-effectiveness analysis of a pilot 
neonatal screening program for sickle cell anemia in the Republic of Angola. J Pediatr. 2015;167:1314-9. http://dx.doi.org/10.1016/j. jpeds.2015.08.068

37. Burlone S, Edelman AB, Caughey AB, Trussell J, Dantas S, Rodriguez MI. Extending contraceptive coverage under the Affordable Care Act saves public funds. Contraception. 2013;87:1438. http://dx.doi.org/10.1016/j.contraception.2012.06.009

38. Frost JJ, Sonfield A, Zolna MR, Finer LB. Return on investment: a fuller assessment of the benefits and cost savings of the US publicly funded family planning program. Milbank Q. 2014;92:696-749. http://dx.doi.org/10.1111/1468-0009.12080
39. Center for Work Force Studies. 2015 state physician workforce data book. Washington: Association of American Medical Colleges; 2015.

40. Bishaw A, Fontenot K. Poverty: 2012 and 2013 [cited 2016 May 20]. https://www.census.gov/content/dam/Census/library/ publications/2014/acs/acsbr13-01.pdf

Address for correspondence: Rui Li, Centers for Disease Control and Prevention, 4770 Buford Hwy NE, Mailstop F-74, Atlanta, GA 30341, USA; email: ruili@cdc.gov

\section{August 2014: Vector-borne Diseases}

- Leptospirosis-Associated Hospitalizations, United States, 1998-2009

- Independent Origin of Plasmodium falciparum Antifolate SuperResistance, Uganda, Tanzania, and Ethiopia

- Global and Local Persistence of Influenza $\mathrm{A}(\mathrm{H} 5 \mathrm{~N} 1)$ Virus

- Human Exposure to Live Poultry and Psychological and Behavioral Responses to Influenza A(H7N9), China

- Rapid Whole-Genome Sequencing for Surveillance of Salmonella enterica Serovar Enteritidis

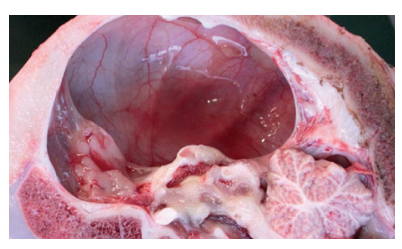

- Novel Reassortant Influenza A(H5N8)

Viruses in Domestic Ducks, Eastern China

- Antibodies against MERS Coronavirus in Dromedary Camels, Kenya, 1992-2013

- Borrelia crocidurae Infection in Acutely Febrile Patients, Senegal
- Shelter Dogs as Sentinels for Trypanosoma cruzi Transmission across Texas, USA

- Natural Intrauterine Infection with Schmallenberg Virus in Malformed Newborn Calves

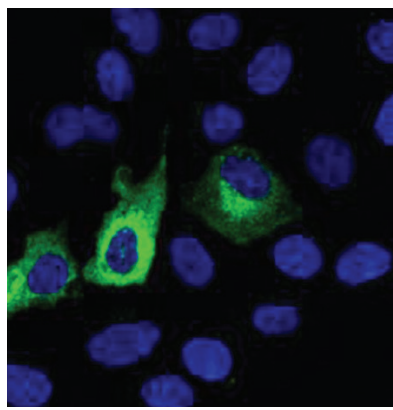

- Role of Migratory Birds in Spreading CrimeanCongo Hemorrhagic Fever, Turkey

- Isolation of MERS Coronavirus from Dromedary Camel, Qatar, 2014

- New Introductions of Enterovirus 71

Subgenogroup C4 Strains, France, 2012

- Rapid Detection, Complete Genome Sequencing, and Phylogenetic Analysis of Porcine Deltacoronavirus
- Geographic Distribution of MERS Coronavirus among Dromedary Camels, Africa

- Human Infections with Borrelia miyamotoi, Japan

- Co-circulation of Dengue and Chikungunya Viruses, $\mathrm{Al}$ Hudaydah, Yemen, 2012

- Antibodies against Severe Fever with Thrombocytopenia Syndrome Virus in Healthy Persons, China, 2013

- Severe Fever with Thrombocytopenia Syndrome Virus in Ticks Collected from Humans, South Korea, 2013

- Infection with Possible Precursor of Avian Influenza A(H7N9) Virus in a Child, China, 2013

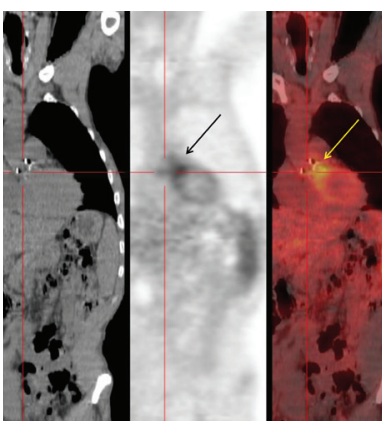

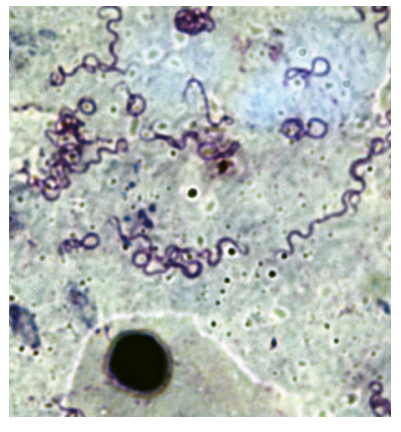

- Dengue Virus

Transmission by Blood Stem Cell Donor after Travel to Sri Lanka, 2012

- Severe Murine Typhus with Pulmonary System Involvement

- Detection of East/Central/ South African Genotype of Chikungunya Virus in Myanmar, 2010

- Pulmonary Infection and Colonization with Nontuberculous Mycobacteria, Taiwan, 2000-2012

- Levofloxacin-Resistant Haemophilus influenzae, Taiwan, 2004-2010

- Movement of Chikungunya Virus into the Western Hemisphere

- Diagnosis of Bartonella henselae Prosthetic Valve Endocarditis in Man, France 